\title{
PLUTO: Inferactive
}

\section{instruction on the Web}

\author{
By Ann Margaret Scholz, Richard Cary Kerr, and Samuel Keith Brown
}

\section{Purdue University's online orientation program}

コ ach year large academic research libraries welcome thousands of new students who enter the university with varying levels of information literacy skills. Orienting this vast number of students in an effective and efficient manner is one of our greatest challenges. If we are successful in our efforts, subsequent instruction will be facilitated because students will have a solid foundation of basic knowledge on which to build the more conceptual understanding of the research process.

At Purdue University, 6,000 to 7,000 new students enter the West Lafayette campus each year. Given the finite number of instructional librarian staff, all entering students cannot be reached through individual class contacts. Even if this personal contact were possible, the question of addressing the varying levels of student knowledge in a single class session remains. Currently many schools and departments within Purdue University require an orientation course. Individual subject librarians may be invited to provide one 50-minute session on library resources to some of these courses. Recently, development of a systemwide general orientation course which would be required of all students has been proposed. Taking a proactive approach to improve library instruction in existing orientation courses, the libraries have created a readily accessible interactive, learnercentered World Wide Web information literacy module called PLUTO (Purdue Libraries Undergraduate Tutorial Online).

Purdue University Libraries have been involved with computer-assisted instruction in PCand Macintosh-based hypertext environments since the early 1980 s. $^{.}$Since that time, new opportunities in networking and advanced communications have been developed which allow global access to instruction through the Internet. The advantages of offering instruction over the Web include its learner-centered environment, global access, easy update procedures, and cross-platform use. Some disadvantages of this medium include lack of display control for differing browsers, inability to access the entire program on nongraphical browsers, and lack of

Figure 1.

\section{Registration Form}

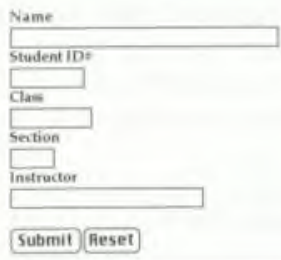

Ann Margaret Scholz is user instmuction librarian at Purdue University Libraries, e-mail: scbolz@purdue.edu; Richard Cary Kerr is network administrator at Purdue, e-mail; cary@lib.purdue.edu; Samuel Keith Brown is student programmer at Purdue, e-mail: brownsk@ib.purdue.edu. 
personal contact with students.

The general intention of the libraries' orientation program is to concentrate on a few essential skills such as beginning database searching and orienting students to THOR, the local online system. The program is designed to whet the student's appetite by covering skills he or she is likely to use in the first year of college. PLUTO contains an interactive tutorial and a quiz section which are integrated together through a series of hypertext links. Students complete the entire program online and orientation instructors later receive students' registration and completion information.

\section{Planning}

Planning for PLUTO began in February 1995. During this time, learning objectives were identified, program requirements were outlined, partnerships were formed with the libraries' Information Technology Department, and funding for equipment and staff time were secured.

Interviews were conducted with Purdue librarians, classroom instructors, and student government organizations to determine key objectives that orientation-level instruction should include. From this feedback, three primary learning objectives were established. After completing PLUTO, a student should be able to:

- define and formulate keyword searches on a given topic;

- retrieve information on a topic from THOR, the libraries' online system; and

- locate information from THOR within the Purdue Libraries System.

Physical orientation to the libraries would be available to beginning students through a number of existing programs including an audio tour of the Undergraduate Library and a videotape.

Once learning objectives were identified, a basic structure for the program was outlined and program requirements were identified. Requirements included necessary program functions that would facilitate program use, tracking abilities, and instructor notification, includ-

\section{Your Current Status}

ing: online student registration; an interactive quiz with online feedback and links back to relevant tutorial pages; the ability to track students through the tutorial and quiz; and an easy method for gathering the names of students who had completed the program. A full-time student programmer was hired for three months to program these functions. Graphical software, file converters, and a color scanner were purchased.

\section{Development}

Prior to creating any PLUTO pages, an initial storyboard was created which outlined the learning concepts for each of the three identified learning objectives. In developing a basic structure and layout, the user instruction librarian took advantage of hypertext capabilities by including essential information at the top of the tree structure and providing more detail underneath. A great effort was made to keep the program self-contained and of a manageable size, focusing on only the identified objectives and avoiding the temptation to include everything students might need to know for the future. Hypertext links were provided in every portion of the program as menu links and internal text links to improve user control.

An overall look for the program was designed to include a visually pleasing header and navigational button graphics that would appear on each page. Using the storyboard created earlier, the user instruction librarian began writing the PLUTO tutorial in html format 
and creating the format for the PLUTO quizzes.

After PLUTO's basic structure was identified, the user instruction librarian discussed the program requirements with the libraries' network administrator and worked out a schedule for implementation of specific programs, e.g., the registration process. The network administrator then selected a student programmer for the PLUTO project and began training and educating the student on programming in a Web environment.

The programmer created several CGI (Common Gateway Interface) programs to support page tracking, automated registration, and random questioning. By August, PLUTO pages and programming were complete. Various test groups were used to work out possible programming bugs and linking errors and feedback was sought from all undergraduate librarians.

\section{Program}

The PLUTO program is composed of two main parts: a tutorial and two quizzes. The tutorial uses the three objectives to form its primary structure and the quizzes test knowledge learned within the tutorial. Students may begin PLUTO by selecting any one of the stated objectives or by selecting to begin the quizzes immediately.

When a student enters the PLUTO program, each page accessed and all quiz answers are

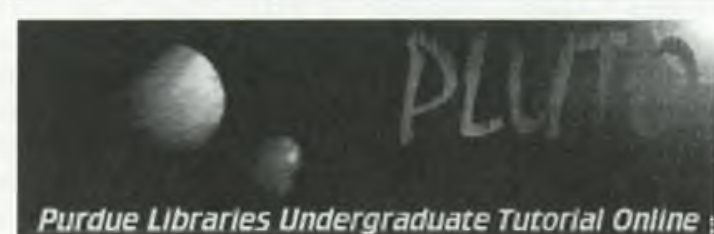

\section{General Information}

\section{How to register \& use PLUTO \\ ${ }^{a}$ General info on Purdue Libraries}

About the PLUTO Project

\section{PLUTO Tutorial}

"Keyword Searching

- THOR, THe Online Resource

a Locating THOR Material tracked and linked to registration information. Defined fields for registration include student name, course, instructor, and section (see figure 1). Students may check their PLUTO status at any time by returning to the quiz introduction page and selecting the status link (see figure 2).

The PLUTO tutorial is divided into three sections covering basic keyword search principles, Purdue's online system, and interpreting online information (see figure 3). Each section has a number of subtopics which the student can view within the PLUTO menu. The keyword section covers why students would use keyword searching, how to choose search terms, and how to combine keywords into phrases and concepts.

The online system section covers what an online system is, databases contained in the system, basic searches, and specifics on the mechanics of keyword searching the system. The third section covers how to interpret information found on an online screen including differences between book and journal records, linking article information to holdings information, and basic view commands.

The two quizzes in PLUTO are programmed so that when a user selects a link to begin or continue a quiz, a question is randomly presented. Students must successfully complete a specified number of questions from each quiz and must complete the first quiz before the second. The number of incorrect responses does not affect the student's overall success.

The first quiz tests four basic principles of keyword searching that are explained within the tutorial. Students are provided with a topic and given three keyword search statements (see figure 4). From the three search statements, students choose the most inappropriate search statement for that topic. Once the answer is selected, students are informed of their success. Regardless of the outcome, students are provided with an explanation of why search statements are acceptable or not, with links back to relevant portions of the PLUTO tutorial. Once students complete the specified number of questions successfully, they are informed

Figure 3. 
of their success and are given the option of reentering the PLUTO tutorial or continuing to the next quiz.

The second quiz tests for comprehension of THOR screen information. Students are provided with a sample database screen and given a question about the screen information which appears, e.g., which library would contain a copy of the article or book listed. The student then selects the appropriate area of the screen by clicking the mouse arrow on the piece of information which answers the question. Once an answer is selected, students are informed of their success and provided with further explanation of the screen.

Upon completion of the second quiz, PLUTO prompts the student to inform his or her instructor. If the student has not already registered, he or she is provided with a link to do so. With the registration process completed, the student is prompted by a completion screen of his or her success. A log file of completion screens includes all registration information, time spent from start to finish, and all pages accessed. This information is imported to a spreadsheet program where individual fields are defined and manipulated for instructor reports.

\section{Implementation}

During the early stages of PLUTO development, the lead instructor for an orientation class in the Schools of Engineering agreed to have five sections of 40 students each participate in a beta test for PLUTO. First-year engineering students were selected because the Schools of Engineering provides a computer skills training program for entering students which includes Web instruction. In the initial stages of implementation, we were more concerned with the tutorial and programming than with teaching students the mechanics of a Web browser.

In October, instruction sessions were scheduled with each section. PLUTO was one of four course projects given in the first-year engineering orientation course and counted for five percent of the overall grade.

During the classroom sessions, students were given instructions for accessing and using the
PLUTO program. Sessions held in the libraries Electronic Classroom allowed students to access the program and view key portions, but actual completion took place outside of class time. Ninety-three percent of the students completed the PLUTO program within the four weeks provided. The primary browser used to access the program both in and outside of the classroom was Netscape. Nongraphical browsers, such as Lynx, do not support PLUTO because of the large amount of graphics included within the program.

A follow-up assignment reinforced the principles taught in the PLUTO program. In the assignment, students were provided with a topic and told to search by keyword for relevant articles, locate one retrieved article, and summarize its main points. Topics were related to the course assignment of developing a resume and writing a cover letter. While the user instruction librarian designed the assignment and provided the search topics, classroom instructors graded the follow-up assignment.

\section{Future}

PLUTO will be revised and refined and made ready for a wider audience this fall. Initial feedback suggests the need for more links within each quiz response and enhancements in the registration process.

In the future, we hope to add other instructional modules including research strategies for Internet resources and discipline-specific instruction. Students could elect to enter other modules from the PLUTO completion screen.

\section{Note}

1. Judith M., Pask, "Computer-Assisted Instruction for Basic Library Skills," Library Software Review 7 (1988): 6-11. 


\section{INFORMATION COMES IN ALL}

\section{SHAPES AND SIZES}

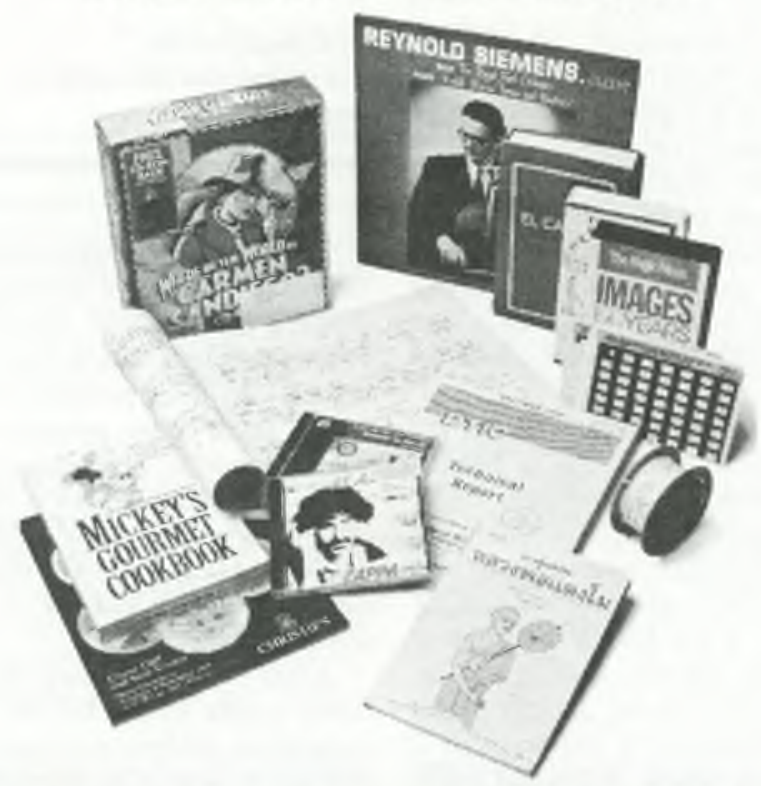

\section{OCLC's TECHPRO Service catalogs it all}

With library resources so stretched, it's challenging to keep your cataloging upto-date. And it's frustrating, because uncataloged materials are inaccessible to your patrons.

OCLC's TECHPRO Service can help. Since 1985, we've offered solutions for libraries that have cataloging backlogs or need ongoing cataloging support.

- Customized cataloging and physical processing to match your specifications

- Cataloging for all bibliographic formats and many languages

- Quality cataloging at prices that can reduce your overall cataloging costs

Contract cataloging for books, serials, scores, non-print items, foreign language materials and more-it's cataloging in all shapes and sizes-from OCLC's TECHPRO Service.

1.800-848.5878, ext. 4386

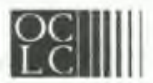

